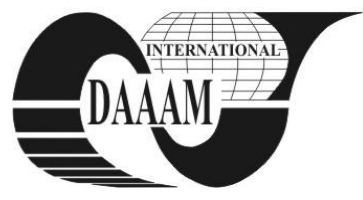

\title{
MORE EFFICIENT STUDYING IN COMPLEX STUDIES DUE TO ELEMENTARY CONTROL OF WORKLOAD ON AN EXAMPLE IN THE DEGREE PROGRAM MECHATRONICS/ROBOTICS
}

\author{
MALISA, V[iktorio] \& KOMENDA, T[itanilla] V[anessa]
}

\begin{abstract}
The purpose of this paper is to assist in the weekly assessment of students' workload and to optimize learning outcomes in the degree program Mechatronics/Robotics by means of an ECTS-barometer. The European Credit Transfer and Accumulation System developed so called ECTS credits, which can be used to capture learning activities of students on a weekly basis. As the degree program Mechatronics/Robotics consists of a number of disciplines the allocation of workloads and associated assignments can be optimized with the implementation of the ECTS-barometer so as to avoid overloads.
\end{abstract}

Key words: efficient studying, ECTS-barometer, workload, mechatronics, robotics

\section{INTRODUCTION}

The European Credit Transfer and Accumulation System (ECTS) has been developed in order to be able to compare course achievements across Europe. This transparency of learning outcomes allows for the academic authentication of course achievements abroad. The main purpose of ECTS is to "facilitate planning, delivery, evaluation, recognition and validation of qualifications and units of learning as well as student mobility. Learning outcomes describe what a student is expected to know, understand and be able to do after successful completion of a process of learning, whereas workload indicates the time students typically need to complete all learning activities (such as lectures, seminars, projects, practical work, self-study and examinations) required to achieve the expected learning outcomes" (European Commission, 2010). As the field of Mechatronics consists of a number of disciplines, allocated learning activities can overtax students. Hence, ECTS credits can be used to illustrate course achievements on a weekly basis so as to avoid overloads. Those credits provide information of the required learning outcomes for each lesson and indicate the time students typically need to complete the requested learning activities for each lesson respectively. As a result, the announcement of weekly course achievements could help to improve learning outcomes in the degree program Mechatronics/Robotics while not sacrificing too much of Mechatronic relevant knowledge.

\section{THE COMPLEX CHARACTER MECHATRONICS/ROBOTICS}

The modern definition of Mechatronics includes the synergistic interaction of different technologies. In order to be able to design Mechatronic systems the so called added value of the synergetic effect is of high importance (Bradley, 2004). With the added value it is possible to implement innovative functionality and control complex systems. The feature of Mechatronics is to combine special areas (shownin Fig. 1). As represented, Mechatronics is defined by the sum of three special area modules with the added value of Mechatronics: From each part Mechanics, Electronics and Computer Science

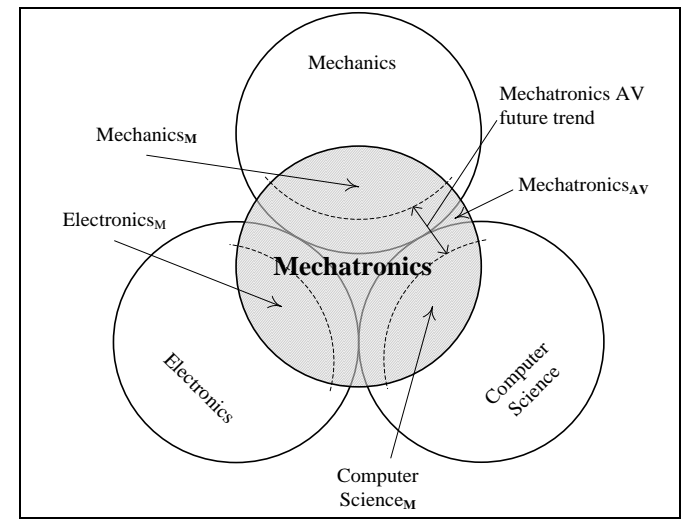

Fig. 1. Graphical definition of Mechatronics with a representation of the added value (Malisa and Hieger, 2009)

the main focus for Mechatronics is defined and an added value for the Mechatronics science is added. (Malisa and Hieger, 2009)

The added value $\left(\mathrm{M}_{\mathrm{AV}}\right)$ describes the modality how the three fields of Mechanics, Electronics and Computer Science are combined and work together. The Mechatronics engineer is related to an effort of solving technological problems using interdisciplinary knowledge among mechanical engineering, electronics and computer technology. As further developments in Mechatronics will form and increase the Mechatronics added value, a reposition of Mechatronics will occur and the Mechatronics engineer must be able to act as an interpreter of all these fields.

It is evident, that Mechatronics including the specialization in Robotics is a rather complex degree program due to the synergetic combination of three engineering fields. During the development of the curriculum of the degree program Mechatronics/Robotics lecturers are confronted with the challenge to impart high amounts of knowledge of the three special area modules within the Mechatronics discipline while not causing overloads.

\section{ECTS CREDITS CONTROL WORKLOAD}

According to the Bologna Framework, 60 ECTS credits are attached to the workload of a full-time year of formal learning (academic year) and the associated learning outcomes. Based on an average workload of 1500 hours for an academic year in Austria, one credit corresponds to 25 hours of work. As one term (half of an academic year) has 15 weeks, so students are expected to spend 50 hours per week engaged in learning activities. 50 hours, in turn, correspond to 2 ECTS credits. Here it should be kept in mind that these numbers represent average students.

Furthermore, the course achievement is divided into hours of attendance and hours of self-study. On the one hand, hours of attendance are considered as the time, a student spends in the classroom. On the other hand, hours of required self-study are 
defined as the time, a student spends on projects, preparing presentations or studying for exams. During one term approximately 20 hours of lecture units (1 lecture unit corresponds to 45 minutes) per week are scheduled. This results in 225 hours of attendance per term, meaning that students have to engage about 525 hours of self-study. (Malisa und Komenda, 2010)

In planning a term for students in the degree program Mechatronics/Robotics, the student schedule only shows the hours of attendance, which correspond to about $30 \%$ of the overall learning activities (Malisa, 2008). The remaining 70\% of required study time is not explicit and can be arranged by each lecturer independently. Due to the complexity of the Mechatronic field a more efficient coordination between individual lecturers concerning the dispensation of students' assignments per week is evident and should result in avoiding overloads for students. Furthermore an optimal distribution of workload should be defined.

\section{EFFICIENT STUDYING DUE TO THE IMPLEMENTATION OF THE ECTS- BAROMETER}

With the identification of learning outcomes and the time students typically need to complete requested learning activities for each lesson in the degree program Mechatronics/Robotics respectively, the ECTS-barometer can be implemented to show the students' expected weekly workload. In this sense, lecturers are asked to distribute amount of hours of attendance and selfstudy separately over the whole term. The overall workload per week is calculated by summing up the hours of attendance and the time for self-study of all lectures within one term.

Fig. 2.shows an allocation of workload in the second term of the Master degree program Mechatronics/Robotics as an example. It is evident that the Mechatronics/Robotics course lasts 17 weeks. This is due to holidays and an attempt to reduce the overall workload per week. In Fig. 2.dark bars depict the amount of attendance and light bars the hours of self-study. The ECTS-barometer including its visualization of learning activities provides the possibility to recognize hours with low workload which is helpful in terms of shifting lecture units due to significant overloads in according weeks. Furthermore, students as well as lecturers well prepared for upcoming learning activities.

ECTS-barometers should be implemented above all in complex studies in order to be able to control students' workload. Moreover, the data acquisition processes and the creation of such barometers should be carried out before the beginning of the term. Hence, overloads can be detected in an early scheduling phase and can be considered in the development of time tables. Especially in complex studies lectures run risk of overtaxing their students due to the wide range of the specific study course. With the implementation of the ECTS-barometer lecturers can plan students' schedules so as to optimize their workloads, while not sacrificing too much of the required learning outcomes.

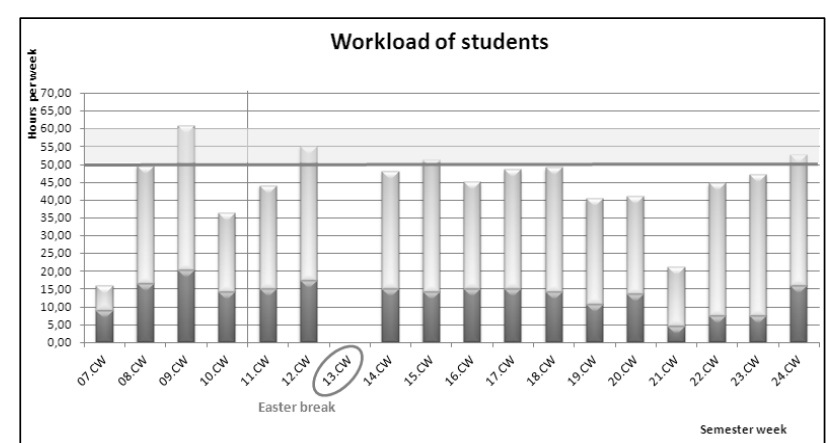

Fig. 2. Allocating of students' workload in the degree program Mechatronics/Robotics (Komenda and Malisa, 2010)

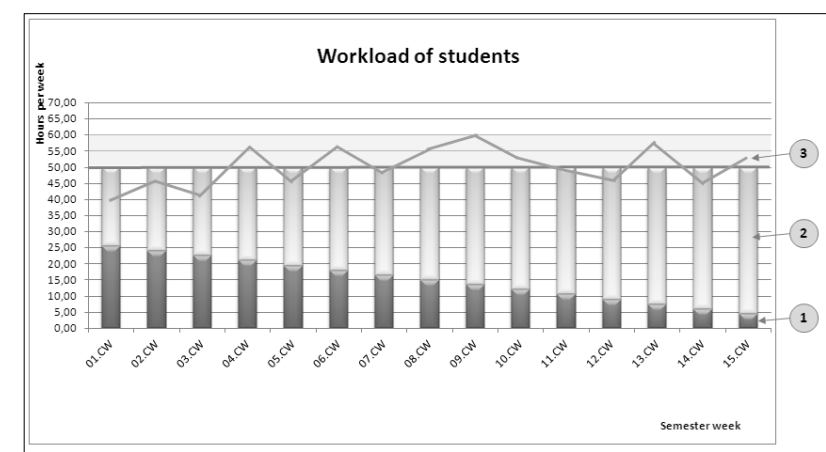

Fig. 3.Optimal allocating of students' workload in the degree program Mechatronics/Robotics

1-hours of attendance, 2-hours of self-study, 3-overall workload

Fig. 3.shows an example of an ideal distribution of the workload of students in the degree program Mechatronics/Robotics while visualizing also the oscillation of real workload. The number of hours of attendance should be high at the beginning and should decrease at the end of the term. This is due to rudimental learning activities at home in the first weeks. In general, lecturers introduce themselves and their study course whereas they do not provide any homework in those weeks. On the other hand, hours of self-study should increase accordingly to the advancing semester. As examinations are generally at the end of the term in the degree program Mechatronics/Robotics, required learning activities should increase significantly at the end of the semester.

\section{CONCLUSION}

Due to the complexity of specific study courses, especially of the degree program Mechatronics/Robotics, the need for an assisting tool in the planning and weekly assessment of students' workload has been evident. ECTS credits have been developed by the European Credit and Accumulation System and can be used to capture learning outcomes on a weekly basis. Based on those credits an ECTS-barometer has been introducedwhich visualizes the hours of attendance and hours students need to complete requested assignments for each lesson respectively. Furthermore, an optimal dispensation of workload has been given. The ECTS-barometer should improve scheduling of learning activities and make overloaded weekstransparent. It should support students as well as lecturers in their efforts to optimize learning outcomes.

\section{REFERENCES}

Bradley, D. (2004). What is Mechatronics and why teach it, International Journal of Electrical Engineering Education, pg. 41/4, October

European Commission (2010).European Credit Transfer and Accumulation System $\quad$ (ECTS).Available from:http://ec.europa.eu/education/lifelong-learningpolicy/doc48_en.htm.Accessed: 2010-05-31

Komenda, T.; Malisa, V. (2010).Implementation of the ECTSbarometer to illustrate course achievement using the Master degree program Mechatronics/Robotics as a model.Joint International IGIP-SEFI Annual Conference, Trnava, September 2010

Malisa, V. (2008).ECTS-Barometer zur Darstellung der Studienleistung. 5. Fachwissenschaftliches Kolloquium „Angewandte Automatisierungstechnik in Lehre und Entwicklung " (AALE) an der Hochschule Harz in Wernigerode, Wernigerode, 2008

Malisa, V.; Hieger, C. (2009).Graphical Analysis about the definition of Mechatronics, $20^{\text {th }}$ International DAAAM Symposium, Vienna, November 2009 